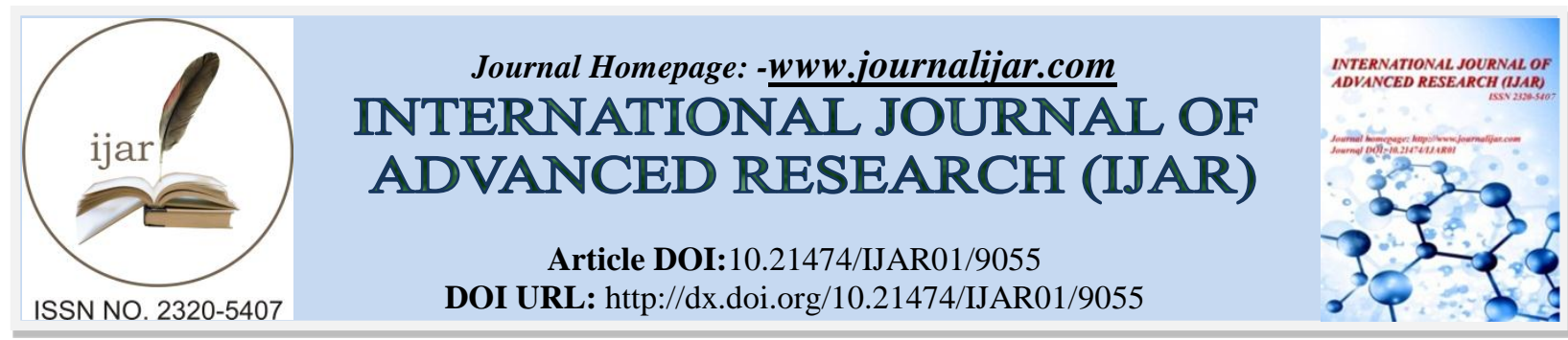

RESEARCH ARTICLE

\title{
SONOGRAPHIC FINDINGS IN HYPERTENSIVE PATIENTS SUSPECTED TO HAVE RENAL ARTERY STENOSIS AT MOI TEACHING AND REFERRAL HOSPITAL, ELDORET, KENYA.
}

\author{
Alung'at Omasete $\mathbf{M}^{1}$, Abuya Joseph ${ }^{2}$ and Kimutai Ezekiel ${ }^{3}$. \\ 1. Resident, Department of Radiology and Imaging, School of Medicine, Moi University, Eldoret, Kenya. \\ 2. Senior Lecturer, Department of Radiology and Imaging, School of Medicine, Moi University, Eldoret, Kenya. \\ 3. Consultant Radiologist and Head of Department, Department of Radiology, Moi Teaching and Referral \\ Hospital, Eldoret, Kenya.
}

\section{Manuscript Info}

(n........................

Manuscript History

Received: 12 March 2019

Final Accepted: 14 April 2019

Published: May 2019

Key words:-

Renal artery stenosis, Parvus-Tardus waveform, Renal Doppler Studies.

\section{Abstract}

Background: Renal artery stenosis is the leading cause of secondary hypertension. Global prevalence of hypertension is $22 \%$ and across the WHO regions it is highest in Africa (30\%). Up to 5\% (3.5 to 4 million) of all occurrences of hypertension in the United States are caused by renal artery stenosis. The prevalence varies according to the population examined. This prevalence in our region is unknown and the diagnosis is probably missed in many patients. Timely diagnosis is important since renal artery stenosis is a correctable cause of hypertension.

Objectives: To describe sonographic findings and determine the prevalence of renal artery stenosis in adult hypertensive patients suspected to have renal artery stenosis at Moi Teaching and Referral Hospital.

Methods: This was a cross sectional study done at the ultrasound room in the Department of Radiology and Imaging, Moi Teaching and Referral Hospital, Eldoret between October 2015 and October 2016. Consecutive sampling technique was used on consenting adult hypertensive patients with clinical features suggestive of renal artery stenosis as per the American Heart association Guidelines of 2005 who underwent renal Duplex Doppler ultrasonography. A 3.5- $7 \mathrm{MHz}$ curvilinear phase array transducer of a Philips HD11 XE machine model 2006 was used. All the images were reviewed by two consultant radiologists. Descriptive statistics were summarized for patient sociodemographics. Frequency tables were generated for categorical variables. Inferential statistics were done using Chi-square and Fishers exact tests. Results were presented using tables and charts.

Results: The study included 169 participants with a median age of 46 (IQR 30). One hundred and five (62.1\%) of them were females. In the findings; Sonographic prevalence of renal artery stenosis was $33.7 \%$. Areas of aliasing was present in $62.5 \%$ of those with renal artery stenosis, post stenotic turbulence in $75.4 \%$ and thickening and calcification of arterial wall in 3.6\%. Tardus- Parvus waveform pattern was seen in $66.1 \%$ (on the right) and $64.9 \%$ (on the left) in patients with renal artery stenosis. Echogenic kidneys were seen in 25 (43.9\%) and loss of cortico medullary differentiation in $15(26.3 \%)$ of the 
patients with renal artery stenosis. More females (63.2\%) had renal artery stenosis than males, and majority, $(43.8 \%)$ of those with renal artery stenosis were above 55 years.

Conclusion: The sonographic prevalence of renal artery stenosis in adult hypertensive patients with specific clinical clues at MTRH was $33.7 \%$. Parvus- Tardus was the commonest waveform pattern seen.

Copy Right, IJAR, 2019,. All rights reserved.

\section{Introduction:-}

Renal artery stenosis (RAS) is the most common surgically or interventionally curable cause of hypertension. Screening and diagnostic tests are still needed to establish its presence ${ }^{1}$.

Timely diagnosis is important because this condition carries a worse prognosis than essential hypertension and seems to be less amenable to drug treatment ${ }^{2}$.

Because of the possibility of cure, screening measures for renal artery stenosis are warranted in hypertensive patients with clinical features suggestive of renovascular disease. Diagnosing these patients is therefore important, since interventional treatment may eliminate or reduce the need for antihypertensive therapy and also preserve renal function $^{3}$.

Duplex Doppler ultrasound is a non-invasive method which is an important part of the diagnostic algorithm in patients with diseases characterized by vascular involvement such as hypertension ${ }^{4}$. It has been extensively used in detecting renovascular diseases, showing to be a non-invasive, safe, low cost and repeatable tool ${ }^{5}$.

Renal duplex Doppler ultrasonography is used in many centers as the first line imaging modality for renovascular diseases. It has been shown to have comparable outcome with angiography which is the gold- standard ${ }^{6,7,8,9}$.

Despite the availability of Renal Duplex Doppler Ultrasound, evaluation of hypertensive patients in our setting is mostly by history taking and clinical examination and radiological investigations are rarely requested by the clinicians unless co morbid conditions exist for example renal failure

Renovascular disease is a general term used to describe lesions of the renal artery, including stenosis and occlusions that can result in significant reduction in renal parenchymal perfusion ${ }^{10}$.

Peng et al, (2015) retrospectively analysed the etiology of RAS in 2047 patients diagnosed with RAS at Fuwai Hospital, China between 1999-2014. They found the causes as atherosclerosis 81.5\%, Takayasu's arteritis $12.7 \%$, fibromuscular dysplasia $4.2 \%$, and other causes $1.6 \%{ }^{11}$.

Atherosclerosis accounts for $90 \%$ of the cases of renal artery stenosis and usually involves the ostium and proximal third of the main renal artery and the perirenal aorta whereas fibromuscular dysplasia accounts for less than $10 \% .90$ $\%$ of cases of fibromuscular dysplasia involve the media. It tends to affect girls and women between 15-50 years of age and frequently involves the distal two thirds of the renal artery and its branches ${ }^{12}$.

Duplex Doppler ultrasound of the renal arteries has replaced other modalities as the screening test of choice in many centers and it is the diagnostic procedure of choice for screening outpatients for RAS ${ }^{13,14}$.

It combines traditional ultrasound imaging with a Doppler technique to measure blood flow velocities in the renal arteries.

Renal Doppler sonography correctly identifies the presence of renovascular disease with an overall accuracy of approximately $95 \%$ and is widely accepted as the first line diagnostic imaging test because of its availability and cost $^{7,15}$. Renal Doppler ultrasound has also been found to be accurate in the diagnosis of significant RAS by Abuagala and Pei (2014) who compared the sensitivity, specificity, accuracy and predictive values of Doppler ultrasonography using contrast- enhanced magnetic resonance imaging as the gold standard for diagnosing RAS. 57 
consecutive patients with clinical findings suggestive of RAS were referred to University Kebangsaan Medical Centre, Kuala Lumpur to be screened for RAS using Doppler ultrasonography and Contrast Enhanced Magnetic Resonance Angiography (CEMRA) as gold standard. They found all the measured Doppler ultrasonography parameters were positive for the detection of RAS with an accuracy of $98.3 \%{ }^{6}$.

Strandness et al (1994) compared results of renal Duplex Doppler scanning with arteriograms in a study done to determine the accuracy of ultrasonic Duplex Doppler scanning in detecting and classifying RAS in Washington. Duplex Doppler scanning identified the location of the renal artery stenosis with an accuracy of $95 \%$. The study concluded that Duplex Doppler scanning is an accurate method of detecting RAS and provides a suitable method of estimating the degree of narrowing ${ }^{9}$.

The overall sensitivity of Duplex ultrasound compared with arteriography was 0.98, the specificity was 0.98 , positive predictive value was 0.99 and negative predictive value was 0.97 .

The kidneys are usually supplied by a single main renal artery that arises from the aorta just inferior to the origin of the superior mesenteric artery. The main renal arteries travel posterior to the corresponding vein and the right renal artery passes posterior to the inferior vena cava. Accessory renal arteries occur in approximately $20 \%$ of the kidneys. The renal arteries branch into multiple segmental arteries that travel from the renal hilum into the renal sinus. The segmental arteries branch into the interlobar arteries and arcuate arteries ${ }^{16}$.

The normal intrarenal arteries are rarely visible on gray-scale sonography but are visible with colour Doppler analysis. The highest frequency transducer that gives measurable waveforms should be used, supplemented by color or power Doppler to help vessel localization.

Several parameters of the Doppler wave can be measured in the signal obtained from the main renal artery and interlobar arteries. Peak systolic velocity (PSV), End diastolic velocity (EDV), peripheral Resistive Index( RI), acceleration time, acceleration index and Renal/Aortic ratio (RAR) ${ }^{17}$. Doppler tracings should be obtained from within the renal arteries and also from within the kidney ${ }^{18}$. The largest study to date was done by AbuRahma et al, (2012) in USA, to compare Renal Doppler ultrasound imaging vs. angiography and to assess various published Doppler criteria. 313 patients (606 renal arteries) were assessed with both Doppler imaging and angiography. RAS was classified as normal, $<60 \%,>60-90 \%$ and occlusion. PSV of $285 \mathrm{~cm} / \mathrm{s}$ or RAR of 3.7 were found to be better than any combination of PSV, EDVs or RARs in detecting more than $60 \%$ stenosis ${ }^{19}$.

The resistive index (RI) measures the degree of intrarenal arterial impedance. It is calculated using the formula :( [PSV- EDV] / PSV) and a mean of 3 measurements at each kidney is usually considered. As resistance to blood flow progressively increases from the hilar arteries towards the more peripheral parenchymal vessels, it is recommended that sampling for RI should be done at the level of the arcuate or interlobar arteries, adjacent to medullary pyramids. Measurements should preferentially be repeated in different parts of both organs ( superior, median and lower) when at least three reproducible waveforms have been obtained ${ }^{20}$.

Several studies have shown that a normal mean RI is approximately $0.60^{21,22}$. In general, most sonologists now consider 0.70 to be the upper threshold of the normal RI in an adult ${ }^{23}$.

Normal renal length (ultrasonic measurement) ranges between $10-12 \mathrm{~cm}$ with a volume of $50-200 \mathrm{~cm}^{3}$. This should be related to the patient's age and build, including height and weight ${ }^{24}$.

Musa (2014) in Sudan studied renal changes in hypertensive patients in high altitude and found reduced kidney length and volume in patients with renal artery stenosis and hypertension compared to those with hypertension alone. On the right he found a mean kidney length of $8.8 \mathrm{~cm}$ and mean volume of $57 \pm 8.11 \mathrm{~cm}^{3}$ and on the left a mean length of $9.0 \mathrm{~cm}$ and renal volume of $55 \pm 9.2 \mathrm{~cm}^{3}$ in patients with RAS. In those without RAS he found a mean length of $9 \pm 0.4 \mathrm{~cm}$ and volume of $85.8 \pm 17.3 \mathrm{~cm}^{3}$ on the right and $9.5 \pm 6.2 \mathrm{~cm}$ and a volume of $89.2 \pm 16.7 \mathrm{~cm}^{3}$ on the left ${ }^{25}$.

In South Western Nigeria Adedeji et al, (2010) evaluated renal volumes in hypertensive patients by ultrasound and found normal kidney volumes. The range of renal volume obtained was 51.6- $205 \mathrm{~cm}^{3}$ with a mean of $114 \mathrm{~cm}^{3}$ for the left kidney and $\left(47.37-177.5 \mathrm{~cm}^{3)}\right.$ with a mean of $106.14 \mathrm{~cm}^{3}$ for the right kidney ${ }^{26}$. 


\section{Methods:-}

The study was carried out in the ultrasound section of Radiology and Imaging Department in Moi Teaching and Referral Hospital (MTRH) in Kenya. It was cross-sectional hospital based study done within a period of one year from October 2015 October 2016. Adult hypertensive patients with clinical features suggestive of renal artery stenosis who met the inclusion criteria and were referred for a Duplex Doppler ultrasound of the kidneys were assessed.

Patients with clinical features of renal artery stenosis were selected since in the general hypertensive population the prevalence varies between 1- 5\% unlike in patients with suggestive clinical features where it varies from $20-40 \%$. Studies have shown that the prevalence of RAS among patients with clinical features suggestive of renovascular disease is $40 \%{ }^{27}$. Thus in order to be $95 \%$ sure that we got the prevalence of RAS within plus or minus $5 \%$ of the study population prevalence of $40 \%$. The sample size was estimated using the Cochran formula ${ }^{28}$.

Consecutive sampling was employed.

A Phillips HD XE machine model 2006 with 3.5 - $5 \mathrm{MHz}$ curvilinear phase array transducer was used. Every effort was made to use a Doppler angle of less than 60 degrees to provide consistency in Doppler velocity measurements. Patients were examined after an overnight fast in the prone, anterior and lateral decubitus positions and portions of the main renal artery from the origin to the hilum were examined. Hilar examination was also performed by the flank approach with the patient in the right and left decubitus positions. This was particularly useful in patients with excessive bowel gas and obese patients.

The length, width, depth and cortical thickness of each kidney were recorded from the flank position using the Bmode imaging.

The renal volume was calculated and a volume of $50-200 \mathrm{~cm}^{3}$ was considered normal.

Renal parenchymal Doppler signals were also acquired during this examination. Zero degree Doppler angle and a sample volume size of $2 \mathrm{~mm}$ was used to record spectral waveforms from the renal parenchyma of the upper and lower poles of each kidney. Patients were asked to hold their breath during the Doppler sampling.

The abdominal aorta was identified in the sagittal plane at the level of the origin of the superior mesenteric artery. Then the transducer was rotated to 90 degrees and each renal artery origin was located using the left renal vein as a landmark. Doppler sampling and velocity waveforms were obtained from the origin, proximal, middle and distal renal arteries. Peak systolic velocities (PSVs) and end- diastolic velocities (EDV) along both renal arteries from the aortic origin to the renal hilum were also recorded. The RAR was calculated by dividing the highest PSV in the renal artery by the PSV in the aorta.

Resistive index was calculated using the formula ([PSV- EDV] / PSV) and a mean of 3 measurements at each kidney was considered. A value of 0.70 was considered as the upper threshold of normal $\mathrm{RI}^{23}$.

In the direct criteria a peak systolic velocity PSV exceeding $200 \mathrm{~cm} / \mathrm{sec}$ in any abnormal areas, and Renal artery to aortic velocity ratio (RAR) of greater than 3.5 were considered abnormal. In the indirect criteria the Doppler wave characteristics used were presence of any areas of aliasing, localized perivascular tissue vibration, post stenotic turbulence and Parvus- Tardus waveform pattern. Any one or more of the above features were diagnostic of RAS.

Atherosclerotic plaque was diagnosed based on presence of thickening (more than $6 \mathrm{~mm}$ ) and calcification of the wall of the renal artery. Renal artery occlusion was diagnosed when there was no flow signal in the renal artery and a low amplitude velocity signal from the renal parenchyma.

Data was collected using a structured questionnaire. There were internal quality controls of all Ultrasound scans done.

The categorical variables were summarized as frequencies and percentages. Test of associations between such variables were conducted using Pearson's Chi-square test and Fishers exact test. The normally distributed continuous variables were summarized as mean and standard deviation or as median and quartiles for the skewed variables. All the analysis was performed using R statistical package. 


\section{Results:-}

A total of 169 hypertensive patients aged between 18-86 years and presenting with clinical features suggestive of renal artery stenosis participated in the study.

\section{Renal Duplex Doppler Ultrasound Findings}

The mean peak systolic velocity in participants found to have renal artery stenosis was $47 \mathrm{~cm} / \mathrm{sec}$ in both the right and left renal arteries, the mean End diastolic velocity was $12.5 \mathrm{~cm} / \mathrm{sec}$ in the right renal artery and $14.5 \mathrm{~cm} / \mathrm{sec}$ in the left renal artery. The systolic renal to aortic velocity ratio was 3.48 in the right renal artery and 3.23 in the left renal artery whereas the resistive index was 0.6 in both the right and left renal arteries.

The kidney lengths were $7.64 \mathrm{~cm}$ and $7.20 \mathrm{~cm}$ for the right and left kidneys respectively, width $3.77 \mathrm{~cm}$ for both right and left kidneys and depth was $3.84 \mathrm{~cm}$ and $3.85 \mathrm{~cm}$ for the right and left kidneys respectively. Renal cortical thickness was $1.42 \mathrm{~cm}$ and $1.24 \mathrm{~cm}$ for the right and left kidneys respectively.

Table 1:-Summary Of Renal Duplex Doppler Ultrasound Findings in those found to have Renal Artery Stenosis

\begin{tabular}{|c|c|c|c|c|c|c|c|}
\hline Renal characteristic & Kidney & Mean & SD & Median & IQR & Min & $\operatorname{Max}$ \\
\hline \multirow[t]{2}{*}{$\begin{array}{l}\text { Peak systolic } \\
\text { velocity }\end{array}$} & Right $(n=48)$ & 47.31 & 14.49 & 29.20 & 11.30 & 6.60 & 78.30 \\
\hline & Left $(n=57)$ & 47.67 & 20.59 & 35.70 & 27.30 & 12.60 & 107.00 \\
\hline \multirow[t]{2}{*}{$\begin{array}{l}\text { End diastolic } \\
\text { velocity }\end{array}$} & Right $(\mathrm{n}=48)$ & 12.55 & 6.57 & 12.55 & 6.10 & 2.30 & 35.60 \\
\hline & Left $(n=57)$ & 14.59 & 9.25 & 15.10 & 12.37 & 1.08 & 47.20 \\
\hline \multirow[t]{2}{*}{$\begin{array}{l}\text { Systolic renal/ aortic } \\
\text { ratio ( RAR) }\end{array}$} & Right $(n=46)$ & 3.48 & 1.26 & 2.70 & 0.95 & 1.03 & 7.20 \\
\hline & Left $(n=56)$ & 3.23 & 0.69 & 2.62 & 1.05 & 1.64 & 4.25 \\
\hline \multirow[t]{2}{*}{ Resistive Index (RI) } & Right $(\mathrm{n}=48)$ & 0.68 & 0.11 & 0.61 & 0.14 & 0.38 & 0.86 \\
\hline & Left $(n=57)$ & 0.65 & 0.11 & 0.60 & 0.15 & 0.39 & 0.97 \\
\hline \multirow[t]{2}{*}{$\begin{array}{l}\text { Systolic / diastolic (SD) } \\
\text { ratio }\end{array}$} & Right $(\mathrm{n}=42)$ & 0.89 & 0.67 & 0.77 & 0.49 & 0.16 & 3.50 \\
\hline & Left $(n=47)$ & 1.05 & 0.90 & 0.80 & 0.68 & 0.20 & 3.87 \\
\hline \multirow[t]{2}{*}{ Length $(\mathrm{cm})$} & Right $(n=57)$ & 7.64 & 1.40 & 8.25 & 2.38 & 5.0 & 9.80 \\
\hline & Left $(n=57)$ & 7.20 & 1.30 & 8.27 & 2.12 & 5.78 & 10.0 \\
\hline \multirow[t]{2}{*}{ width $(\mathrm{cm})$} & Right $(n=57)$ & 3.77 & 0.76 & 3.79 & 1.03 & 2.30 & 5.51 \\
\hline & Left $(n=57)$ & 3.77 & 0.56 & 3.60 & 0.62 & 2.76 & 5.10 \\
\hline \multirow[t]{2}{*}{ depth $(\mathrm{cm})$} & Right $(\mathrm{n}=55)$ & 3.84 & 1.04 & 3.93 & 1.18 & 1.45 & 6.96 \\
\hline & Left $(n=55)$ & 3.85 & 0.76 & 3.71 & 0.71 & 2.50 & 5.70 \\
\hline \multirow[t]{2}{*}{$\begin{array}{l}\text { Renal cortical } \\
\text { thickness }\end{array}$} & Right $(n=43)$ & 1.42 & 0.36 & 1.36 & 0.45 & 0.60 & 2.10 \\
\hline & Left $(n=48)$ & 1.24 & 0.33 & 1.22 & 0.43 & 0.12 & 1.81 \\
\hline
\end{tabular}

In the participants who did not have renal arteries stenosis as shown in the table below; the mean peak systolic velocity was $32.9 \mathrm{~cm} / \mathrm{sec}$ and $37.81 \mathrm{~cm} / \mathrm{sec}$ in the right and left renal arteries respectively. The mean End diastolic velocity was $14.74 \mathrm{~cm} / \mathrm{sec}$ in the right renal artery and $17.82 \mathrm{~cm} / \mathrm{sec}$ in the left renal artery. The systolic renal to aortic velocity ratio was 2.93 in the right renal artery and 2.80 in the left renal artery whereas the resistive index was 0.6 in both the right and left renal arteries.

The kidney lengths were $8.57 \mathrm{~cm}$ and $8.66 \mathrm{~cm}$ for the right and left kidneys respectively, width $4.48 \mathrm{~cm}$ for the right kidney and $4.22 \mathrm{~cm}$ for the left kidney and depth was $4.34 \mathrm{~cm}$ and $4.36 \mathrm{~cm}$ for the right and left kidneys respectively. Renal cortical thickness was $1.27 \mathrm{~cm}$ and $1.26 \mathrm{~cm}$ for the right and left kidneys respectively. 
Table 2:-Summary Of Renal Duplex DopplerUltrasound Findings In Those With No Renal Artery Stenosis

\begin{tabular}{|c|c|c|c|c|c|c|c|}
\hline Renal characteristic & Kidney & Mean & SD & Median & IQR & Min & Max \\
\hline \multirow[t]{2}{*}{$\begin{array}{l}\text { Peak systolic } \\
\text { velocity }\end{array}$} & Right (n=108) & 32.91 & 15.82 & 47.60 & 21.60 & 19.20 & 84.00 \\
\hline & Left $(n=112)$ & 37.81 & 13.71 & 46.50 & 16.20 & 25.90 & 81.10 \\
\hline \multirow[t]{2}{*}{$\begin{array}{l}\text { End diastolic } \\
\text { velocity }\end{array}$} & Right $(\mathrm{n}=108)$ & 14.74 & 5.07 & 16.20 & 6.40 & 0.64 & 24.90 \\
\hline & Left $(n=112)$ & 17.82 & 11.12 & 14.00 & 9.15 & 0.64 & 51.90 \\
\hline \multirow[t]{2}{*}{$\begin{array}{l}\text { Systolic renal/ aortic } \\
\text { ratio ( RAR) }\end{array}$} & Right $(\mathrm{n}=94)$ & 2.93 & 1.37 & 3.05 & 1.72 & 1.74 & 8.50 \\
\hline & Left $(n=97)$ & 2.80 & 1.31 & 2.83 & 1.74 & 1.49 & 7.67 \\
\hline \multirow[t]{2}{*}{ Resistive index(RI) } & Right $(n=108)$ & 0.62 & 0.12 & 0.66 & 0.13 & 0.40 & 0.98 \\
\hline & Left $(n=112)$ & 0.61 & 0.14 & 0.64 & 0.16 & 0.33 & 0.98 \\
\hline \multirow[t]{2}{*}{$\begin{array}{l}\text { Systolic/ diastolic (SD) } \\
\text { ratio }\end{array}$} & Right $(\mathrm{n}=98)$ & 1.04 & 0.40 & 1.00 & 0.46 & 0.25 & 2.92 \\
\hline & Left $(n=102)$ & 0.98 & 0.37 & 0.95 & 0.43 & 0.41 & 2.71 \\
\hline \multirow[t]{2}{*}{ Length (cm) } & Right $(n=108)$ & 8.57 & 1.08 & 8.77 & 1.46 & 5.53 & 11.40 \\
\hline & Left $(n=112)$ & 8.66 & 1.31 & 8.79 & 1.26 & 4.58 & 12.10 \\
\hline \multirow[t]{2}{*}{ width(cm) } & Right $(n=108)$ & 4.48 & 1.13 & 4.43 & 1.28 & 2.83 & 8.36 \\
\hline & Left $(\mathrm{n}=112)$ & 4.22 & 0.69 & 4.21 & 1.03 & 2.60 & 6.39 \\
\hline \multirow[t]{2}{*}{ depth (cm) } & Right $(n=105)$ & 4.34 & 1.24 & 4.70 & 1.46 & 1.37 & 6.33 \\
\hline & Left $(n=105)$ & 4.36 & 1.13 & 4.18 & 1.70 & 2.50 & 6.88 \\
\hline \multirow[t]{2}{*}{$\begin{array}{l}\text { Renal cortical } \\
\text { thickness }\end{array}$} & Right $(\mathrm{n}=82)$ & 1.27 & 0.40 & 1.30 & 0.45 & 0.12 & 2.01 \\
\hline & Left $(n=83)$ & 1.26 & 0.31 & 1.23 & 0.34 & 0.14 & 2.09 \\
\hline
\end{tabular}

Post stenotic turbulence and areas of aliasing were the most common Doppler wave characteristics seen in those with renal artery stenosis. Post stenotic turbulence was seen in $24.6 \%$ and areas of aliasing in $37.5 \%$ of patients with RAS. Thickening and calcification of arterial wall was seen in $2 \%$ of patients with renal artery stenosis.

Table 3:-Summary of Renal Spectral Flow Pattern in All Patients

\begin{tabular}{|c|c|c|c|}
\hline Renal spectral flow pattern & Kidney & Frequency & Percent (\%) \\
\hline \multirow[t]{2}{*}{ Normal } & Right $(\mathrm{n}=165)$ & 112 & 67.9 \\
\hline & Left $(n=169)$ & 120 & 71.0 \\
\hline \multirow[t]{2}{*}{ High Resistant } & Right $(\mathrm{n}=165)$ & 3 & 1.8 \\
\hline & Left $(n=169)$ & 0 & 0 \\
\hline \multirow[t]{2}{*}{ Low } & Right $(\mathrm{n}=165)$ & 6 & 3.6 \\
\hline & Left $(n=169)$ & 9 & 5.3 \\
\hline \multirow[t]{2}{*}{ Absent } & Right $(\mathrm{n}=165)$ & 5 & 3.0 \\
\hline & Left $(n=169)$ & 0 & 0 \\
\hline \multirow[t]{2}{*}{ Reversed } & Right $(n=165)$ & 5 & 3.0 \\
\hline & Left $(n=169)$ & 0 & 0 \\
\hline \multirow[t]{2}{*}{ Tardus Parvus } & Right $(n=165)$ & 32 & 19.4 \\
\hline & Left $(n=169)$ & 37 & 21.9 \\
\hline
\end{tabular}




\begin{tabular}{|l|l|l|l|}
\hline Turbulent & Right $(\mathrm{n}=165)$ & 7 & 4.2 \\
\hline & Left $(\mathrm{n}=169)$ & 1 & 0.6 \\
\hline
\end{tabular}

A majority of the respondents had normal right $(67.9 \%)$ and left $(71.0 \%)$ renal spectral flow patterns. High resistance (1.8\%), low (3.6\%), absent (3.0\%) and reversed (3.0\%) renal spectral patterns were observed in a few respondents, where the right kidneys were the only ones affected. Tardus- parvus pattern was seen on the right in $19.4 \%$ of the participants and on the left in $21.9 \%$ of the participants.

\section{Sample Images}

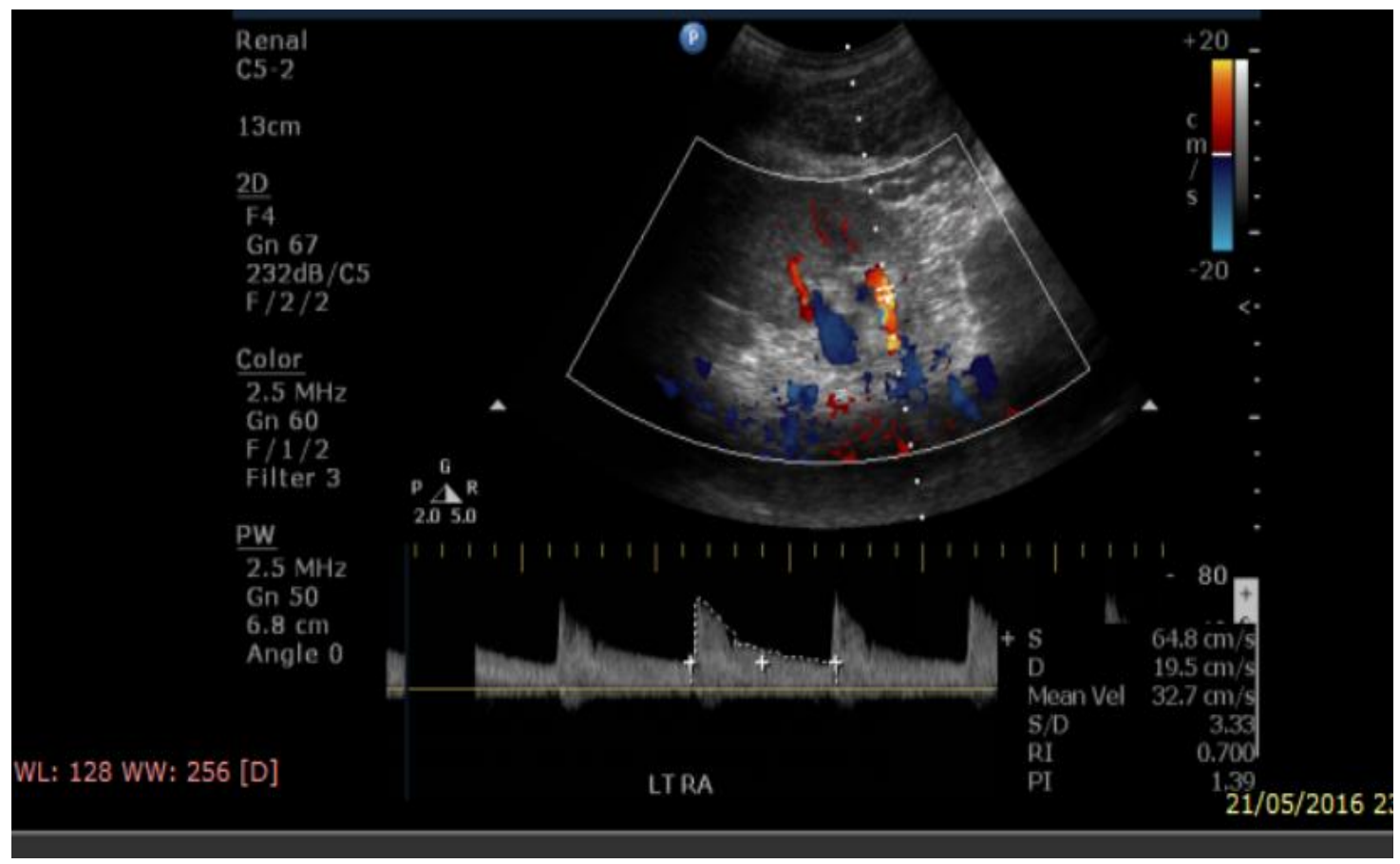

Figure 1:-Normal renal artery waveform pattern showing the normal sharp peak systole.

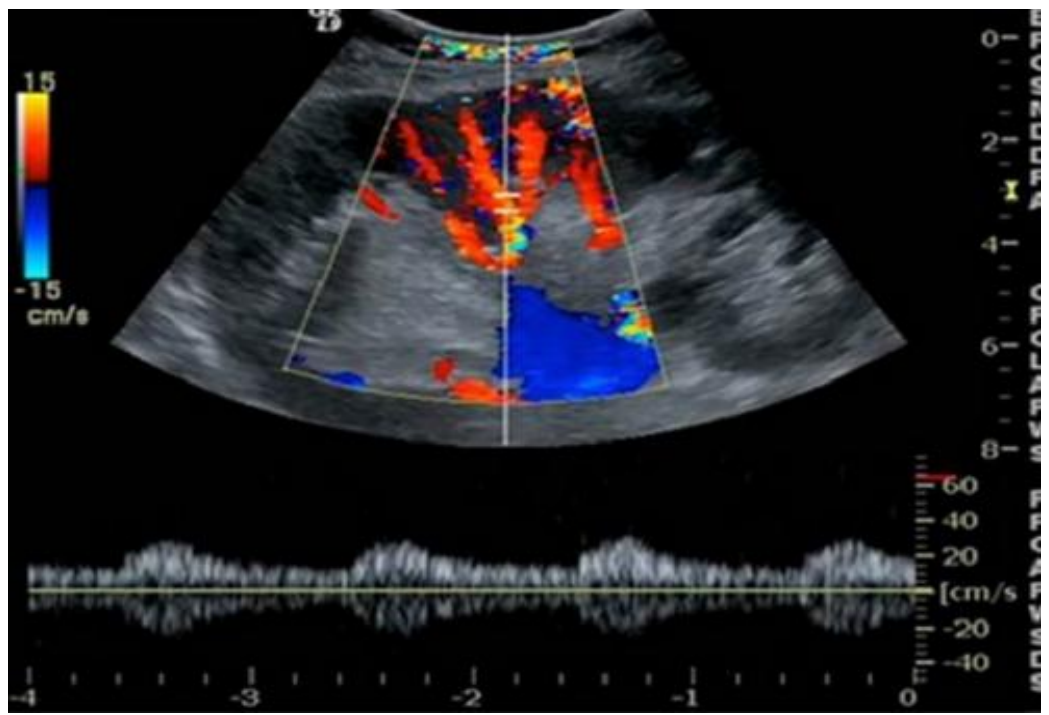

Figure 2:-Severe parvus- tardus waveform pattern of the right renal artery post stenosis.

Parvus- Tardus is a peak systole that is slowed and reduced in amplitude 


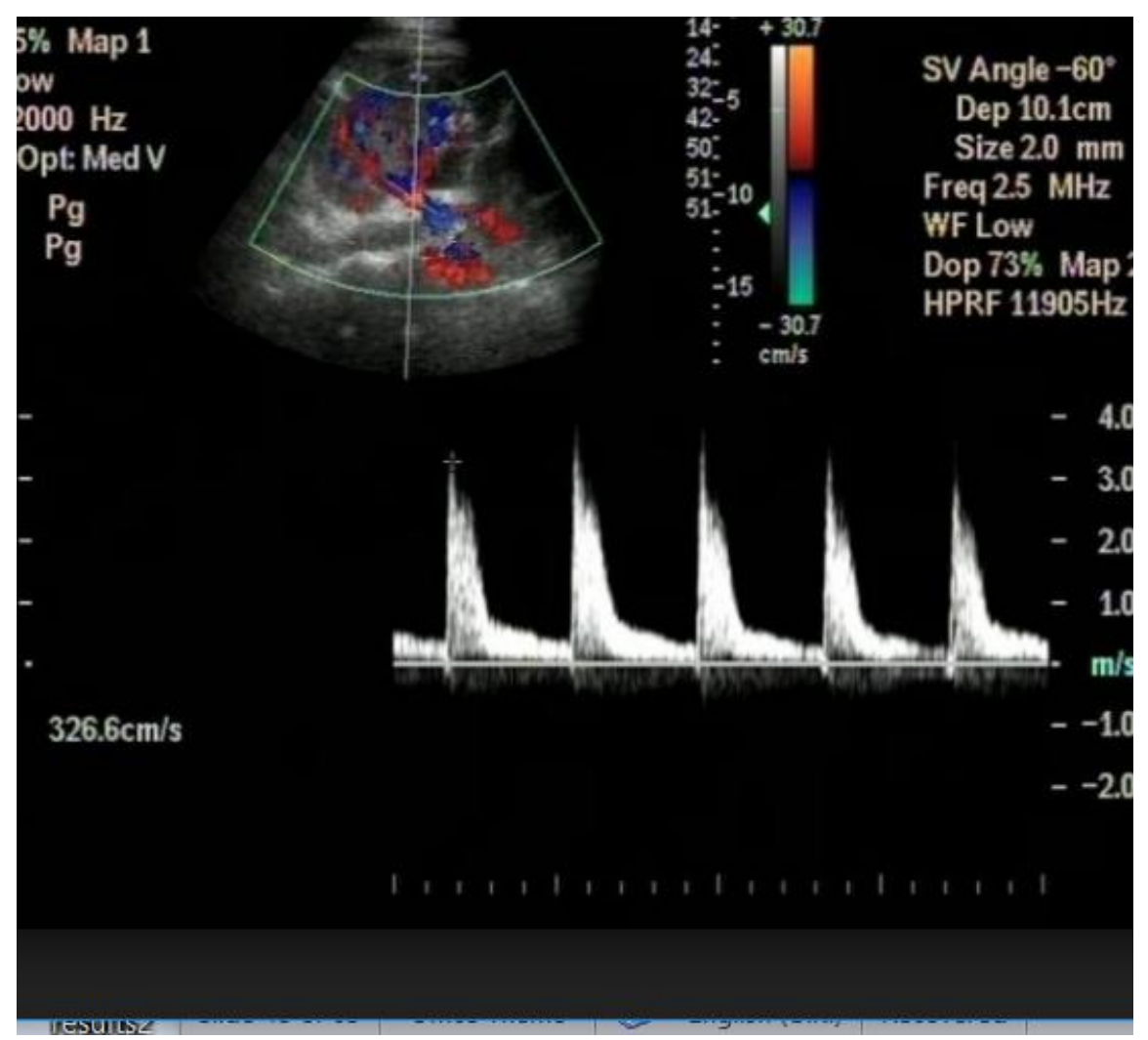

Figure 3:-Showing high PSV at a Stenotic Region.

\section{Discussion:- \\ Sonographic findings in adult hypertensive patients with clinical features of RAS Doppler Parameters}

The mean Peak systolic velocity (PSV) in those found to have renal artery stenosis was $47 \mathrm{~cm} / \mathrm{s}$ in both the right and left renal arteries while in those without renal artery stenosis the mean was $32.9 \mathrm{~cm} / \mathrm{s}$ and $37.8 \mathrm{~cm} / \mathrm{s}$ in the right and left renal arteries respectively. A similar study also found a peak systolic velocity of $37.7 \mathrm{~cm} / \mathrm{s}$ in their study of noninvasive screening for RAS using ultrasound contrast enhancement done in London ${ }^{29}$.

This finding could be attributed to the fact that in both studies a combination of both direct and indirect criteria was used to make the diagnosis of renal artery stenosis, so despite having a normal PSV value the patient could have had other features in the Doppler wave pattern that qualified for stenosis.

Harding et al, (1992) in the Cardiovascular Health Study found a mean PSV of $264 \mathrm{~cm} / \mathrm{sec}$ in patients who had renal artery stenosis. This is because they used only the direct criteria and used only a PSV of above $200 \mathrm{~cm} / \mathrm{sec}$ to make the diagnosis of RAS $^{30}$.

The Renal to Aortic ratio (RAR) in those with renal artery stenosis was found to be 3.48 and 3.23 in the right and left renal arteries respectively. House et al, (1999) in their study of 63 patients using Doppler sonography to evaluate the optimal imaging parameters for renal artery stenosis in the United States found a mean of 3.0. Both studies combined both direct and indirect criteria for evaluating renal artery stenosis ${ }^{31}$.

In our study, the resistive index (RI) was found to be 0.68 and 0.65 in the right and left kidneys respectively in those with renal artery stenosis and 0.62 and 0.61 in the right and left kidneys respectively in those without renal artery stenosis. Similarly Patriquin et al, (1992) in Sainte- Justine Hospital in Montreal, Canada also found lower resistive Indices of 0.43- 0.54 in kidneys with stenotic arteries as compared with healthy subjects. In cases of Renal artery stenosis resistive index will be elevated if measured upstream from the stenosis. The lower RI values could be because the measurements were taken downstream from the stenosis ${ }^{32}$. 


\section{Doppler Wave Characteristics and Spectral Flow Patterns}

Parvus - Tardus waveform pattern was seen in $66.1 \%$ and $64.9 \%$ in the left and right renal arteries respectively in patients with renal artery stenosis. This was similar to findings of Stavros et al, (1992) at the Swedish Medical Centre in Washington who found $61 \%$ in both right and left renal arteries ${ }^{33}$ and Carroll, (1994) at Duke University Medical Centre North Carolina who found $60 \%$ and $62 \%$ in the right and left renal arteries respectively ${ }^{34}$. This finding is because the flow downstream to a significant stenosis is damped and will show a slow rise to peak systole with low height (amplitude) of the wave. Due to its high sensitivity and specificity it is one of the indirect methods highly recommended for evaluation of renal artery stenosis.

Post stenotic turbulence and areas of aliasing were the most common Doppler wave characteristics seen in those with renal artery stenosis. Post stenotic turbulence was seen in $24.6 \%$ and areas of aliasing in $37.5 \%$ in patients with RAS.

Zoller et al, (1990) also found turbulence to be a valuable sign of a hemodynamically significant stenosis ${ }^{35}$. The findings could be attributed to the fact that spectral sampling was done at the point of the stenosis where the velocities were high.

\section{Grey- scale Ultrasound Findings}

In this study the mean kidney lengths for those with renal artery stenosis were reduced; $7.64 \mathrm{~cm}$ and $7.20 \mathrm{~cm}$ for the right and left kidneys respectively compared to those without renal artery stenosis which was $8.57 \mathrm{~cm}$ and $8.66 \mathrm{~cm}$ for the right and left kidneys respectively.

The kidney volumes were also reduced in patients with renal artery stenosis $63.3 \mathrm{~cm}^{3}$ and $59.8 \mathrm{~cm}^{3}$ in the right and left kidneys respectively, compared to $85.3 \mathrm{~cm}^{3}$ on the right and $81.6 \mathrm{~cm}^{3}$ on the left in those without renal artery stenosis.

These findings compare well with a study by Musa, (2014) in Aseer region, Abha ,Saudi Arabia where he used ultrasound to evaluate renal changes in hypertensive patients in a high altitude area. He found a mean kidney length of $8.8 \mathrm{~cm}$ for both kidneys and renal volumes of $57.2 \mathrm{~cm} 3$ in the right and $55.3 \mathrm{~cm} 3$ in the left in patients with renal artery stenosis. These parameters were reduced compared to those without renal artery stenosis ${ }^{25}$. The reduced kidney lengths and volumes in patients with renal artery stenosis could be due to the fact that atherosclerosis which causes stenosis of the renal arteries causes deficiency of blood flow to the kidneys which leads to atrophy.

Adedeji et al, (2015) in South Western Nigeria found normal kidney volumes in patients with hypertension $\left(114 \mathrm{~cm}^{3}\right.$ and $123 \mathrm{~cm}^{3}$ in the right and left kidneys respectively). ${ }^{26}$

The difference in findings could be because they studied hypertensive patients with normal renal functions hence no renal compromise. In our study some of the patients had elevated urea and creatinine levels which denotes some underlying renal compromise. Hypertension tends affect renal volumes when there is a severe underlying renal parenchymal damage or compromise.

Sonographic Prevalence of RAS in Adult Hypertensive Patients with Suggestive Clinical Features.

This study included 169 participants with clinical features suggestive of Renal artery stenosis, this is because the prevalence of renovascular hypertension rises in selected groups of hypertensive patients ${ }^{36}$.

The sonographic prevalence of renal artery stenosis was found to be $33.7 \%$. This is comparable to findings of in Denmark where patients with hypertension and risk factors for peripheral arterial disease were studied ${ }^{37}$. The reason why a high prevalence was found in both studies is because patients with risk factors for renal artery stenosis were studied.

Harding et al, (1992) at Duke University Medical Centre found a prevalence of 30\% which is almost similar to the findings of this study, this is because he studied patients with cardiovascular risk factors which is also a risk factor for $\mathrm{RAS}^{30}$.

Benjamin et al, (2014) at Bayer Heart and vascular Hospital (USA) found a prevalence of $24.2 \%$. The difference could be attributed to the fact that they used conventional angiography which is a different tool from what we used $^{38}$. 


\section{Conclusions:-}

The commonest waveform pattern seen in those with renal artery stenosis was Parvus- Tardus, and it showed a statistically significant association with presence of RAS. The sonographic prevalence of renal artery stenosis was $33.7 \%$.

\section{Acknowledgements:-}

To all those patients who volunteered to this study

\section{References:-}

1. Karasch, T., \& Rubin, J. (1998). Diagnosis of renal artery stenosis and renovascular hypertension. European journal of ultrasound, 7, S27-S39.

2. Derkx, F. H., \& Schalekamp, M. A. (1994). Renal artery stenosis and hypertension. The Lancet, 344(8917), 237-239.

3. Hirsch, A. T., Haskal, Z. J., Hertzer, N. R., Bakal, C. W., Creager, M. A., Halperin, J. L., . . . Puschett, J. B. (2006). ACC/AHA guidelines for the management of patients with peripheral arterial disease (lower extremity, renal, mesenteric, and abdominal aortic). Journal of Vascular and Interventional Radiology, 17(9), 1383-1398.

4. Lubomirova, M., Djerassi, R., Kiperova, B., Boyanov, M., \& Christov, V. (2006). Renal Doppler ultrasound in patients with hypertension and metabolic syndrom. Medicinski pregled, 60, 84-86.

5. Spatola, L., \& Andrulli, S. (2016). Doppler ultrasound in kidney diseases: a key parameter in clinical long-term follow-up. Journal of ultrasound, 19(4), 243-250.

6. Abuagla, E , \& Pei, T. (2014). Utility of color doppler ultrasound in the evaluation of renal artery stenosis in comparison with contrast-enhanced magnetic resonance angiography. Saudi Journal of Kidney Diseases and Transplantation, 25(2), 309.

7. Appel, R. G., Bleyer, A. J., Reavis, S., \& Hansen, K. J. (1995). Renovascular disease in older patients beginning renal replacement therapy. Kidney international, 48(1), 171-176.

8. Olin, J. W., Piedmonte, M. R., Young, J. R., DeAnna, S., Grubb, M., \& Childs, M. B. (1995). The utility of duplex ultrasound scanning of the renal arteries for diagnosing significant renal artery stenosis. Ann Intern Med, 122(11), 833-838.

9. Strandness, D. E. (1994). Duplex imaging for the detection of renal artery stenosis. American Journal of Kidney Diseases, 24(4), 674-678.

10. Norris, C. S., Pfeiffer, J. S., Rittgers, S. E., \& Barnes, R. W. (1984). Noninvasive evaluation of renal artery stenosis and renovascular resistance: experimental and clinical studies. J Vasc Surg, 1(1), 192-201.

11. Peng, M., Jiang, X., Dong, H., Zou, Y., Zhang, H., Song, L., . . . Gao, R. (2015). Etiology of renal artery stenosis in 2047 patients: a single-center retrospective analysis during a 15 -year period in China. Journal of human hypertension.

12. Safian, R. D., \& Textor, S. C. (2001). Renal-artery stenosis. New England Journal of Medicine, 344(6), 431442.

13. Olin, J. W. (2004). Renal artery disease. The Mount Sinai journal of medicine, 71(2), 73.

14. White, C. J., \& Olin, J. W. (2009). Diagnosis and management of atherosclerotic renal artery stenosis: improving patient selection and outcomes. Nature Clinical Practice Cardiovascular Medicine, 6(3), $176-190$.

15. Lao, D., Parasher, P. S., Cho, K. C., \& Yeghiazarians, Y. (2011). Atherosclerotic renal artery stenosisdiagnosis and treatment. Paper presented at the Mayo Clinic Proceedings.

16. Kurtz, A. B., \& Hertzberg, B. S. (2004). Ultrasound: the requisites: Mosby Incorporated.

17. Miralles, M., Cairols, M., Cotillas, J., Giménez, A., \& Santiso, A. (1996). Value of Doppler parameters in the diagnosis of renal artery stenosis. J Vasc Surg, 23(3), 428-435.

18. Rumack, C. M., Wilson, S. R., \& Charboneau, J. W. (2005). Diagnostic ultrasound vol 1: London: Mosby, 2005.

19. AbuRahma, A. F., Srivastava, M., Mousa, A. Y., Dearing, D. D., Hass, S. M., Campbell, J. R., . . Keiffer, T. (2012). Critical analysis of renal duplex ultrasound parameters in detecting significant renal artery stenosis. Journal of vascular surgery, 56(4), 1052-1060. e1051.

20. Tublin, M. E., Bude, R. O., \& Platt, J. F. (2003). The resistive index in renal Doppler sonography: where do we stand? American Journal of Roentgenology, 180(4), 885-892.

21. Keogan, M. T., Kliewer, M. A., Hertzberg, B. S., DeLong, D. M., Tupler, R. H., \& Carroll, B. A. (1996). Renal resistive indexes: variability in Doppler US measurement in a healthy population. Radiology, 199(1), $165-169$. 
22. Kim, S., Kim, W., Choi, B., \& Kim, C. (1990). Duplex sonography of the native kidney-resistive index vs serum creatinine. J Ultrasound Med, 9, S25.

23. Platt, J., Ellis, J., \& Rubin, J. (1991). Examination of native kidneys with duplex Doppler ultrasound. Paper presented at the Seminars in ultrasound, CT, and MR.

24. Emamian, S. A., Nielsen, M. B., Pedersen, J. F., \& Ytte, L. (1993). Kidney dimensions at sonography: correlation with age, sex, and habitus in 665 adult volunteers. AJR. American journal of roentgenology, 160(1), 83-86.

25. Musa, M. J. (2014). Evaluation Of Renal Changes for Hypertensive Patients In High Altitude Using Ultrasonography. Sudan University of Science and Technology.

26. Adedeji, A., Egberongbe, I. I., Adetiloye, V. A., Adeyinka, A. O., Afolabi, O. T., Akintomide, A. O., \& Ayoola, O. O. (2010). Evaluation of renal volume by ultrasonography in patients with essential hypertension in Ile-Ife, south western Nigeria. Libyan journal of medicine Vol 5, 2010.

27. Derkx, F., \& Schalekamp, M. (1994). Renal artery stenosis and hypertension. The Lancet, 344(8917), 237-239.

28. Cochran, W. G. (1965). Sampling Techniques: (2nd Ed): J. Wiley.

29. Missouris, C. G., Allen, C. M., Balen, F. G., Buckenham, T., Lees, W. R., \& MacGregor, G. A. (1996). Noninvasive screening for renal artery stenosis with ultrasound contrast enhancement. Journal of hypertension, 14(4), 519-524.

30. Harding, M. B., Smith, L. R., Himmelstein, S. I., Harrison, K., Phillips, H. R., Schwab, S. J., . . Bashore, T. M. (1992). Renal artery stenosis: prevalence and associated risk factors in patients undergoing routine cardiac catheterization. Journal of the American Society of Nephrology, 2(11), 1608-1616.

31. House, M. K., Dowling, R. J., King, P., \& Gibson, R. N. (1999). Using Doppler sonography to reveal renal artery stenosis: an evaluation of optimal imaging parameters. AJR. American journal of roentgenology, 173(3), 761-765.

32. Patriquin, H. B., Lafortune, M., Jéquier, J.-C., O'Regan, S., Garel, L., Landriault, J., . . Filiatrault, D. (1992). Stenosis of the renal artery: assessment of slowed systole in the downstream circulation with Doppler sonography. Radiology, 184(2), 479-485.

33. Stavros, A., Parker, S., Yakes, W., Chantelois, A., Burke, B., Meyers, P., \& Schenck, J. (1992). Segmental stenosis of the renal artery: pattern recognition of tardus and parvus abnormalities with duplex sonography. Radiology, 184(2), 487-492.

34. Carroll, B. A. (1994). Segmental Stenosis of the Renal Artery: Pattern Recognition of Tardus and Parvus Abnormalities with Duplex Sonograph. Investigative radiology, 29(3), 390-391.

35. Zoller, W., Hermans, H., Bogner, J. R., Hahn, D., \& Middeke, M. (1990). Duplexsonography in the diagnosis of renovascular hypertension. Journal of Molecular Medicine, 68(16), 830-834.

36. Karasch, T., \& Rubin, J. (1998). Diagnosis of renal artery stenosis and renovascular hypertension. European journal of ultrasound, 7, S27-S39.

37. Wachtell, K., Ibsen, H., Olsen, M., Laybourn, C., Christoffersen, J., Nørgaard, H., . . . Lund, J. (1996). Prevalence of renal artery stenosis in patients with peripheral vascular disease and hypertension. Journal of human hypertension, 10(2), 83-85.

38. Benjamin, M. M., Fazel, P., Filardo, G., Choi, J. W., \& Stoler, R. C. (2014). Prevalence of and risk factors of renal artery stenosis in patients with resistant hypertension. The American journal of cardiology, 113(4), 687690 . 